- Supporting Information -

\title{
Role of Alcohol in the Synthesis of CdS Quantum Dots
}

\author{
Frank S. Riehle ${ }^{\dagger, *}$, Kui Yu${ }^{\ddagger *}{ }^{*}$
}

${ }^{+}$Key Laboratory of Solid Waste Treatment and Resource Recycle, School of Environment and Resource, Southwest University of Science and Technology, Mianyang, 621010, P. R. China ${ }^{\ddagger}$ Institute of Atomic and Molecular Physics, Sichuan University, Chengdu, 610065, P. R. China

\section{Corresponding Authors}

*E-mail: frank@swust.edu.cn

*E-mail: kuiyu@scu.edu.cn 


\section{Table of Contents}

Figure S1. Photoluminescence quantum yield calculation of CdS QDs

Figure S2. Picture of $\mathrm{CdS}$ QDs dispersed in $\mathrm{CHCl}_{3}$ under direct sunlight .S5

Figure S3. Statistical TEM analysis of CdS particle mean size .56

Figure S4. CdS particle size estimation from XRD (Scherrer method) S7

Figure S5. Optical comparison (PL) of CdS QDs synthesized via

different

methods (one-pot, injection) . .58

Figure S6. Effect of Cd-to-acid ratio on the particle yield of CdS

QD

S ...

Figure S7. Effect of Cd-to-acid ratio on the PL evolution of CdS

QDs S10

Figure S8. IR spectra of lauric acid and as-prepared cadmium laureate S11

Figure S9. Powder XRD spectrum of as-prepared cadmium laureate S12

Figure S10. Temporal evolution of PL spectra of CdS QDs synthesized with

$$
0.5 \mathrm{M}
$$

TOPS .$S 12$

Figure S11. PL spectrum of a 90min CdS QD sample synthesized with 2MTOPS showing the occurrence of a second nucleation S13

Figure S12. Absorption spectra of CdS QDs synthesized with 2M TOPS 
showing the existence of 311-MSCs

Figure S13. Effect of Cd-to-S ratio and alcohol structure on the formation

of .

CdS MSCs

Figure S14. PL peak evolution or growth curves of CdS QDs synthesized at different precursor

concentrations .$S 15$

Figure S15. Temporal evolution of absorption and PL spectra of CdS

QDs

synthesized at different precursor

concentrations S16

Figure S16. PL peak evolution or growth curves of CdS QDs synthesized in different

alcohols S17

Figure S17. Temporal evolution of PL and absorption spectra of CdS QDs synthesized in secondary and branched alcohols S18

Figure S18. Optical characterization and TEM of CdS QDs synthesized in non-coordinating OD (control experiment) S19

Figure S19. ${ }^{1} \mathrm{H}$ NMR spectrum of 1-decanol in $\mathrm{CDCl}_{3}$ S20

Appendix. Reaction yields calculated from optical data S21 
a)
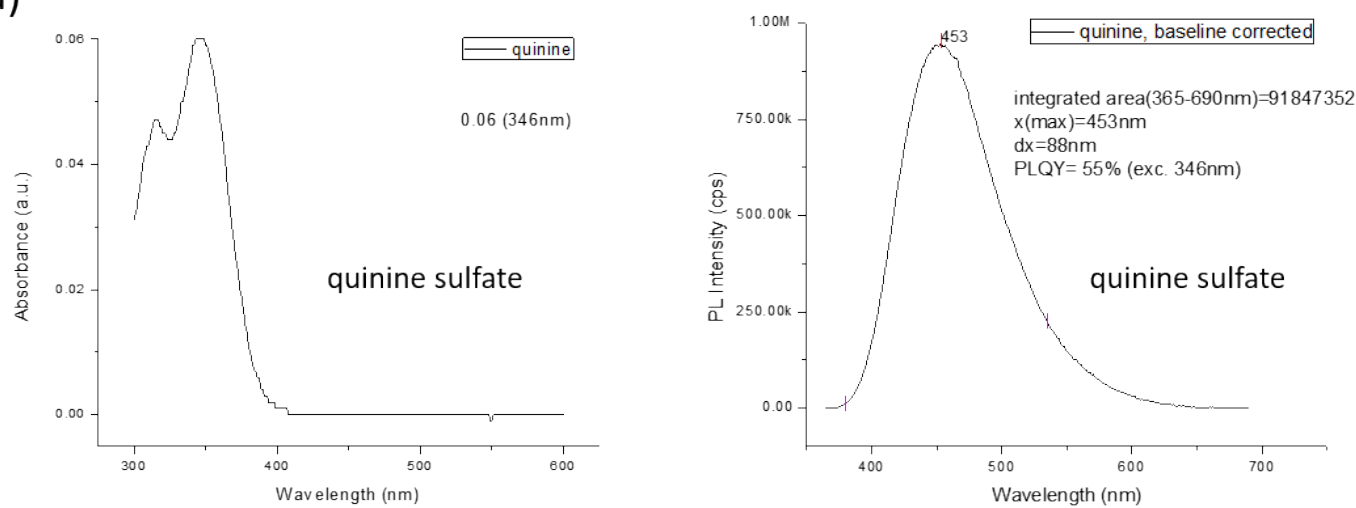

b)
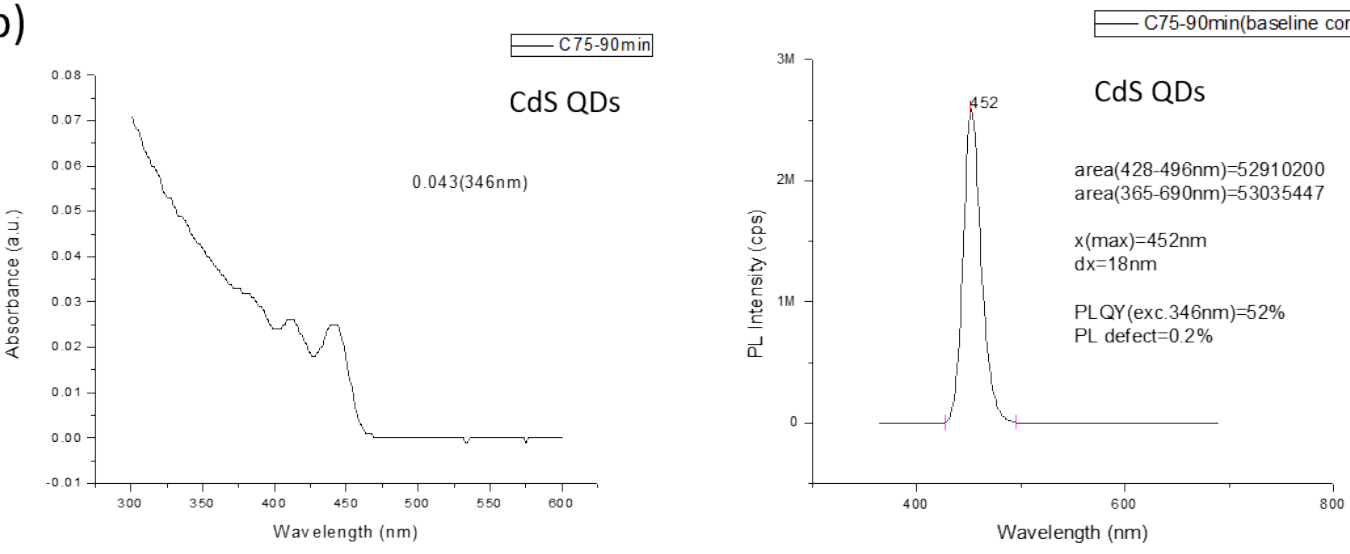

Figure S1. Absorption (left) and PL (right) spectra of a) quinine sulfate in $0.5 \mathrm{M} \mathrm{H}_{2} \mathrm{SO}_{4}$, and b) CdS QDs $\left(180^{\circ} \mathrm{C}-90\right.$ min-sample) in $\mathrm{CHCl}_{3}$. The PL spectra were recorded at $20^{\circ} \mathrm{C}$ using an excitation wavelength of $346 \mathrm{~nm}$. The baseline-corrected PL signals were 
integrated from 365 to $690 \mathrm{~nm}$. A relative PLQY of 52\% (0.2\% defect emission) was calculated for our CdS QDs using the following equation from the reference Standards in Fluorescence Spectrometry, J.N. Miller, Ed., Pub. Chapman and Hall (1981); J. Phys. Chem. 75, 991 (1971): QYQD = QYref $\left(I^{Q D} / /^{\text {ref }}\right)\left(A^{\text {ref }} / A^{Q D}\right)\left(n^{Q D} / n^{\text {ref }}\right)^{2}$.

$Q Y^{N C}=$ relative quantum yield of $Q D ; Q Y^{r e f}=$ quantum yield of the reference dye $=55 \%$ (quinine sulfate at $20^{\circ} \mathrm{C}$ ); $\mathrm{ID}^{\mathrm{DD}}=$ integrated emission peak area of the $\mathrm{QD}=$

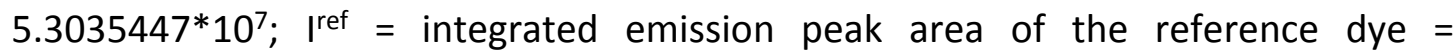
$9.1847352 * 10^{7} ; A^{Q D}=$ Absorbance of the $Q D$ at $346 \mathrm{~nm}=0.043 ; A^{\text {ref }}=$ Absorbance of the reference dye at $346 \mathrm{~nm}=0.060 ; \mathrm{n}^{\mathrm{QD}}=$ refractive indices of the $\mathrm{QD}$ solvent $(1.446$ for $\mathrm{CHCl}_{3}$ at $\left.20^{\circ} \mathrm{C}\right) ; \mathrm{n}^{\text {ref }}=$ refractive index of the solvent of the reference dye $(1.34$ for $0.5 \mathrm{M} \mathrm{H}_{2} \mathrm{SO}_{4}$ in water at $20^{\circ} \mathrm{C}$ ).

$Q Y^{Q D}=55 \%\left(5.3035447 * 10^{7} / 9.1847352 * 10^{7}\right)(0.06 / 0.043)(1.446 / 1.34)^{2}=51.61 \%$ 


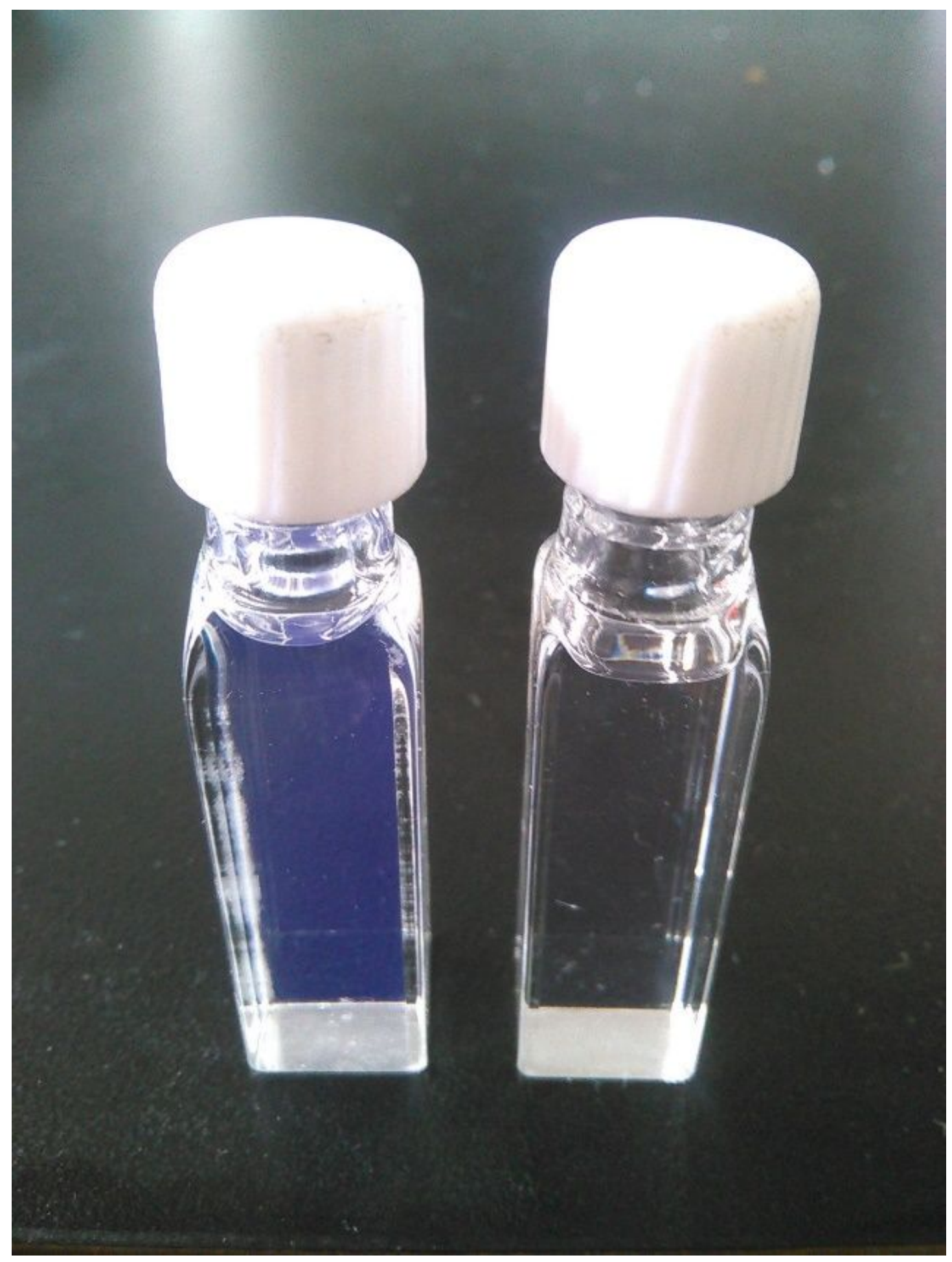

Figure S2: Picture of our CdS QDs (left) dispersed in $\mathrm{CHCl}_{3}$ and pure $\mathrm{CHCl}_{3}$ (right) under sunlight. 

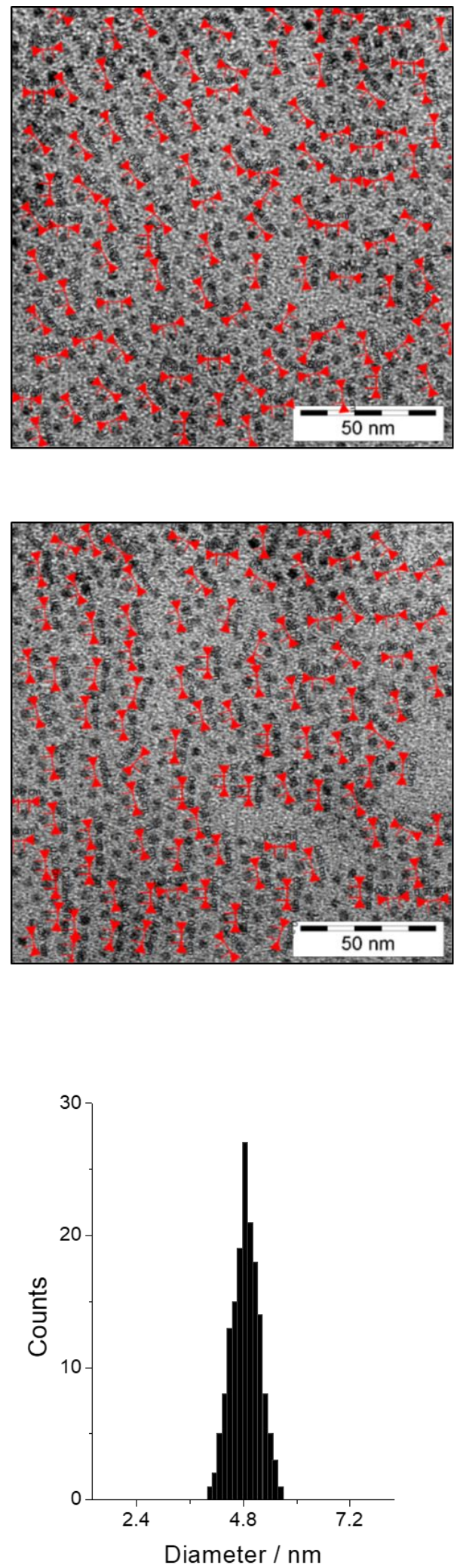

Figure S3. Statistical TEM analysis of our CdS QDs $\left(180^{\circ} \mathrm{C}-90 \mathrm{~min}-\mathrm{sample}\right)$. A mean diameter of $4.88 \pm 0.19 \mathrm{~nm}$ was determined by counting more than 100 particles. The spontaneous formation of 2-dimensional superstructures is attributed to the high size and shape uniformity of the particles. 


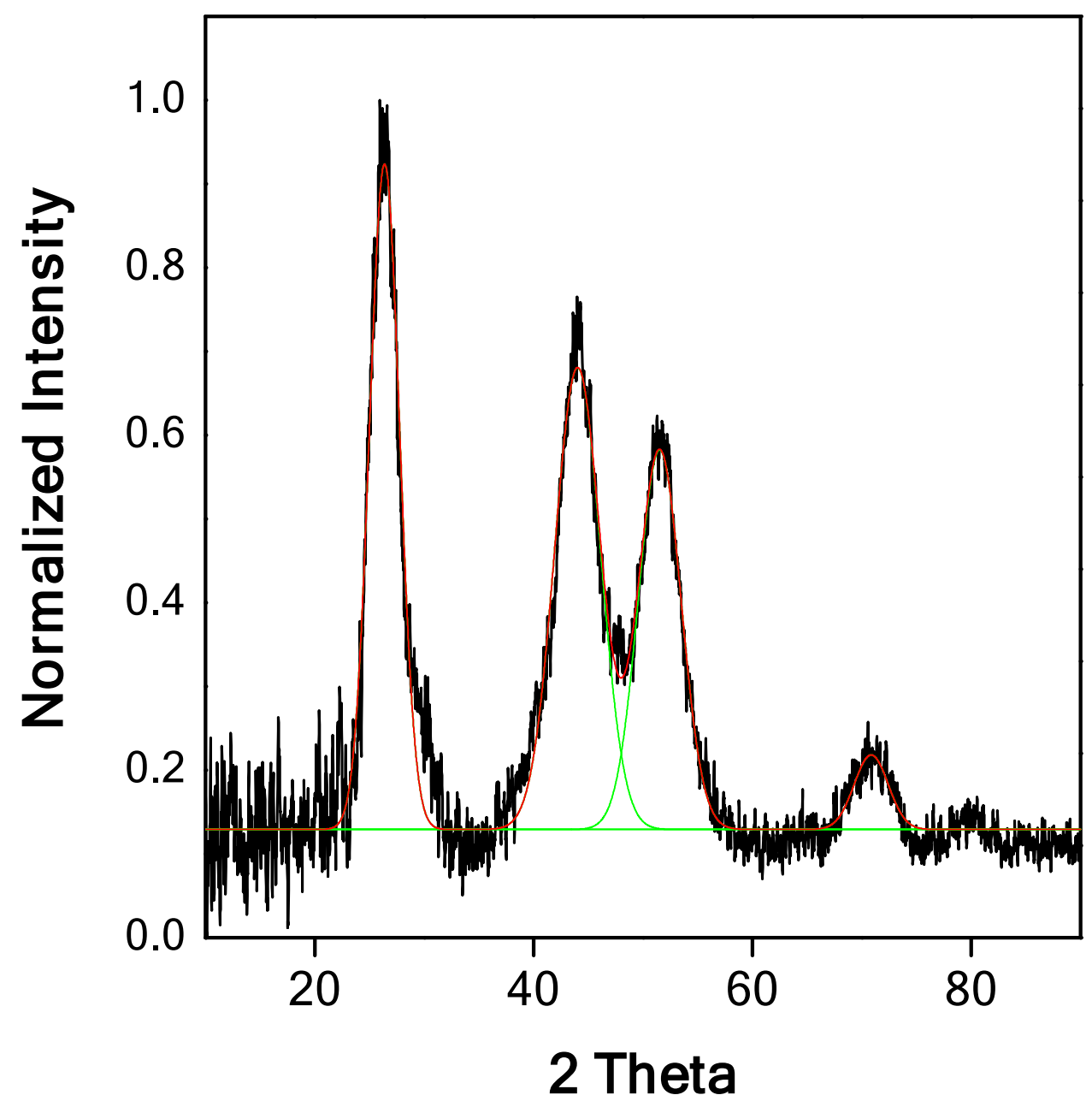

Figure S4. Fitted XRD spectrum (red and green line) of the as-prepared spherical zinc blende CdS QDs ( $180^{\circ} \mathrm{C}-90 \mathrm{~min}$-sample). A minimal particle size of $3 \mathrm{~nm}$ was estimated from the FWHM of the (111) diffraction peak at $26.5^{\circ}$ using the Scherrer equation:

$$
D=K \lambda / \beta \cos \theta
$$

$D$ is the particle diameter, $K$ is a dimensionless shape factor ( 1 for spheres), $\lambda$ is the wavelength of the $X$-ray irradiation $\left(\lambda\left(\mathrm{Cu}-\mathrm{K}_{\alpha 1}\right)=0.154056 \mathrm{~nm}\right), \beta$ is the line broadening at half the maximum intensity (FWHM) after subtracting the instrumental broadening $\left(0.22^{\circ}\right.$ obtained from Si standard at $\left.2 \theta=28^{\circ}\right)$ in radians, and $\theta$ is the Bragg angle. $\theta=13.25^{\circ} ; \beta=(3.24-0.22)^{\circ}=3.02^{\circ} \equiv 0.053$ radians. 
a)

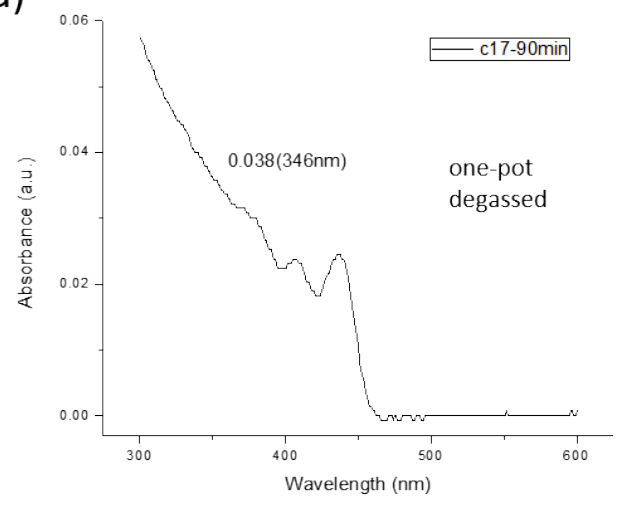

b)

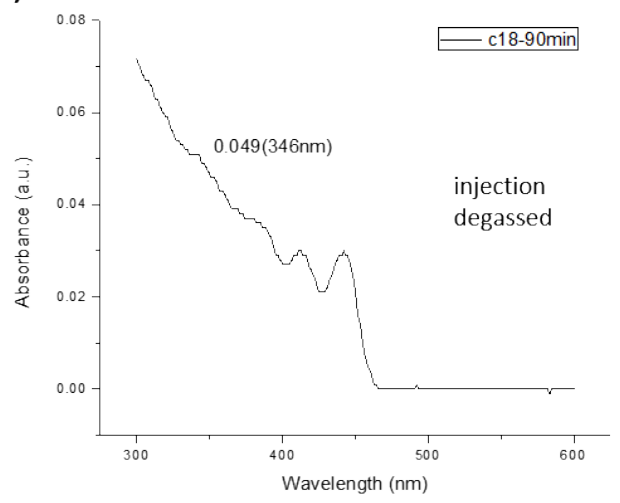

c)

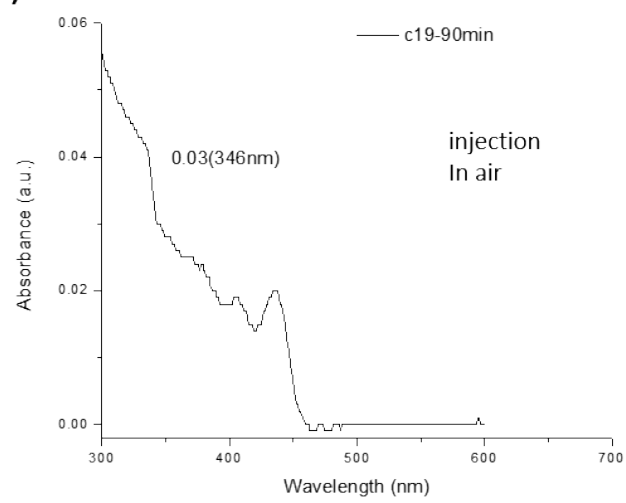

d)

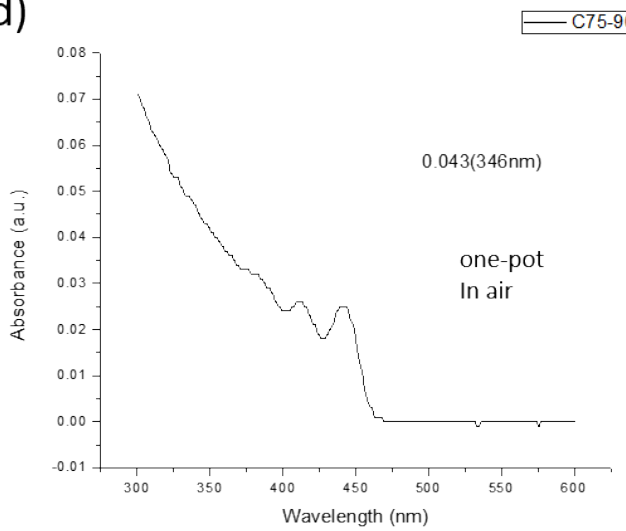

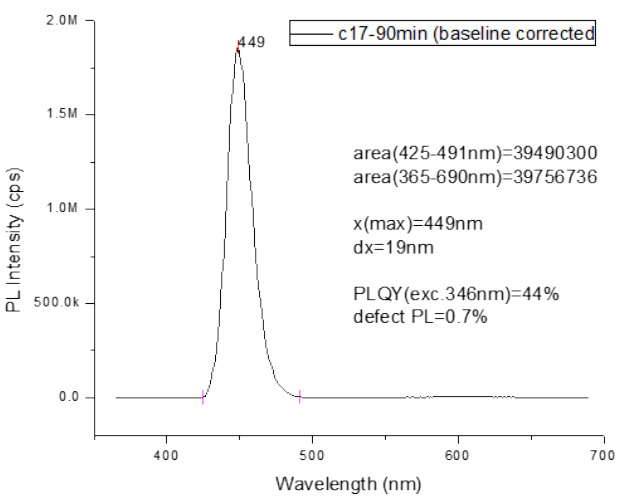
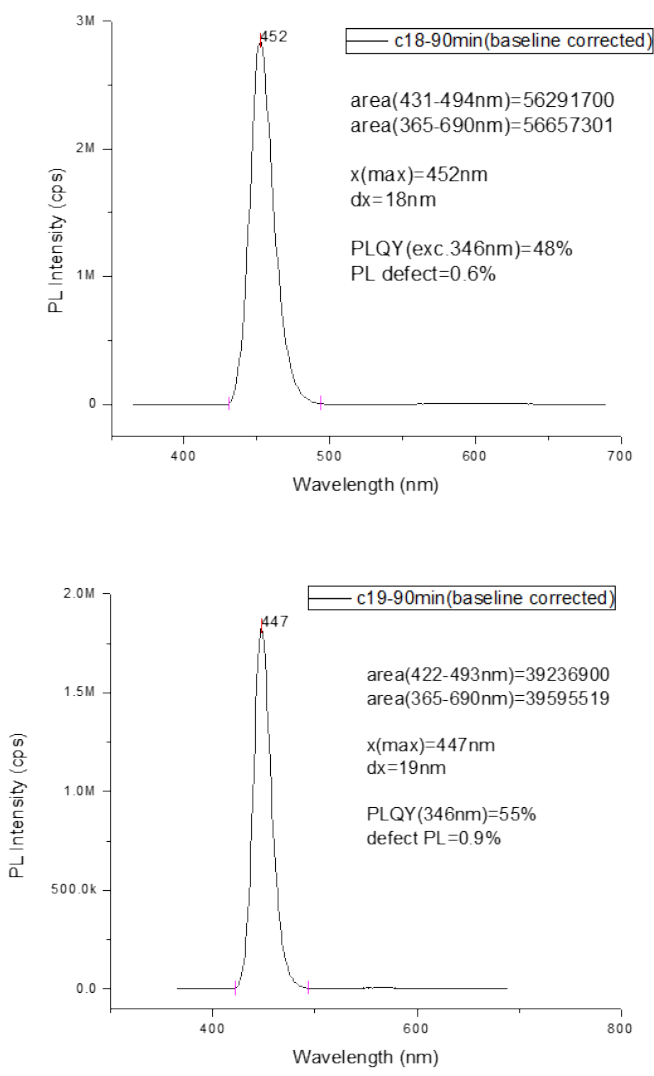

— C75-90min(baseline corrected)

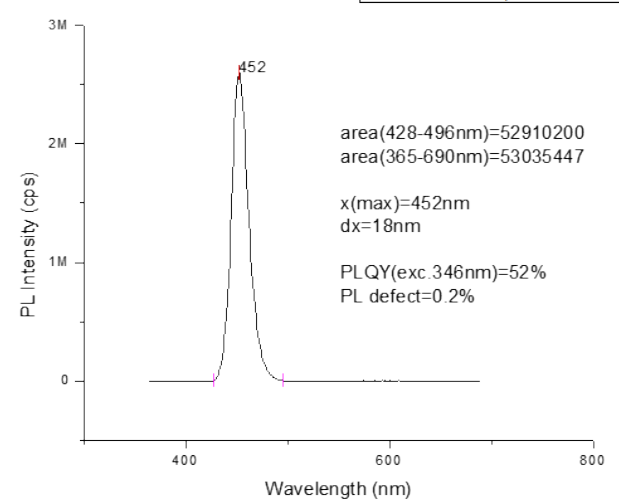

Figure S5. Absorption (left) and PL (right) spectra of CdS QDs $\left(180^{\circ} \mathrm{C}-90 \mathrm{~min}\right.$-samples) 
in $\mathrm{CHCl}_{3}$, synthesized via different methods: a) one-pot (degassed), b) injection (degassed), c) injection (in air), and d) one-pot (in air). The PL spectra were recorded at $20^{\circ} \mathrm{C}$ using an excitation wavelength of $346 \mathrm{~nm}$. The baseline-corrected PL signals were integrated from 365 to $690 \mathrm{~nm}$ and the relative PLQY was calculated in comparison to quinine as the reference dye (see Figure S1). The PLQY values lie within the normal variation of about $5 \%$ for this kind of measurement.

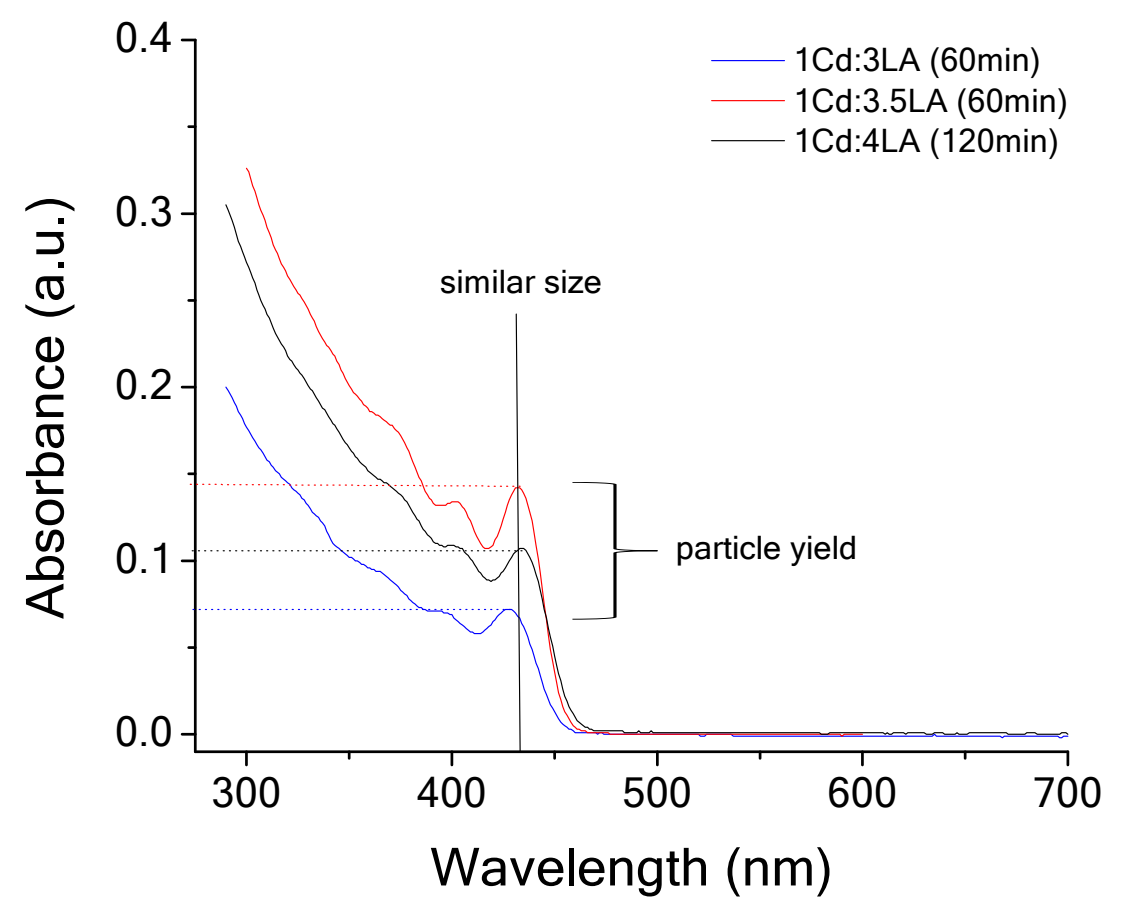

Figure S6. Absorption spectra of similarly sized CdS QDs synthesized from different Cd-to-acid molar ratios: 1:3 (blue line), 1:3.5 (red line), and 1:4 (black line). The different intensities of the absorption peaks located at around $430 \mathrm{~nm}$ reflect the different particle yields (different concentrations of similarly sized particles). The highest particle concentration is found for a Cd-to-acid ratio of 1:3.5. The longer reaction time of $120 \mathrm{~min}$ (instead of $60 \mathrm{~min}$ ) for the 1:4 sample was chosen for the benefit of a better comparison of samples with similar peak positions and does not contradict the general statement. Presuming that CdS QDs are the only reaction product, the particle yield is identical with the reaction yield. 

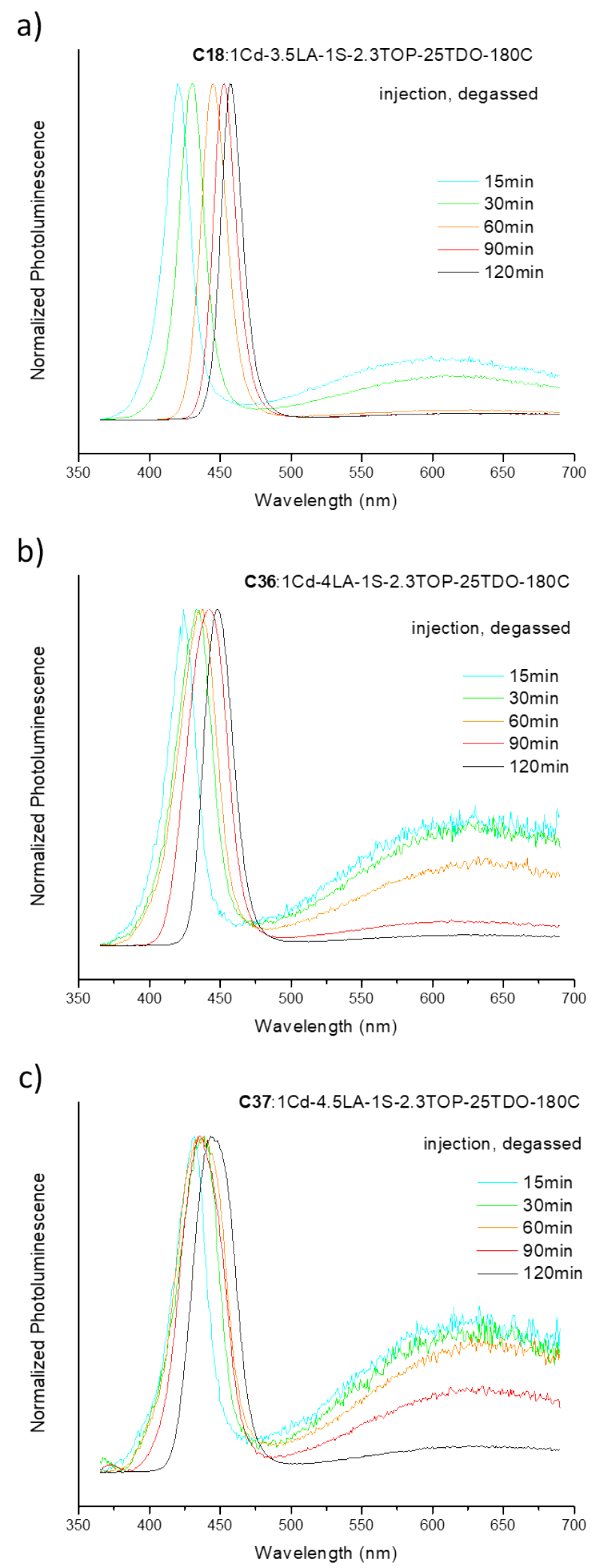

Figure S7. Normalized PL evolution of CdS QDs synthesized from different Cd-to-acid molar ratios: a) 1:3.5, b) 1:4, and c) 1:4.5. With increasing ratio, the defect emission increases relatively to the main PL signal which also becomes broader. 


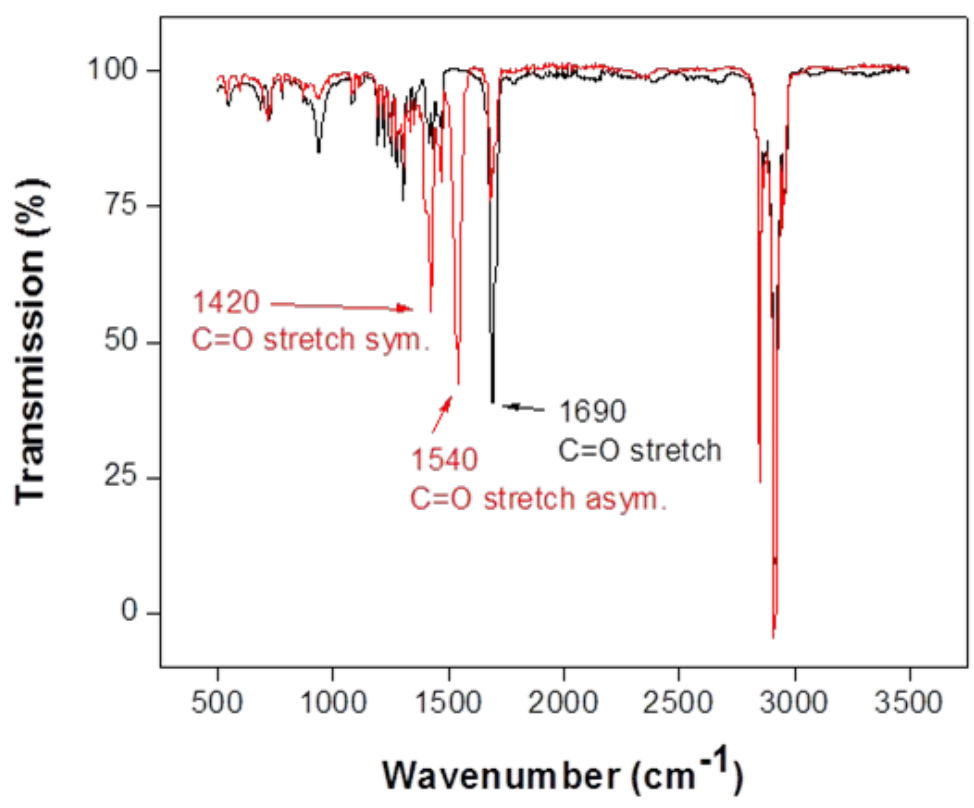

Figure S8. IR spectra of lauric acid (black line) and cadmium laureate (red line) in direct comparison. The two bands at $2910 \mathrm{~cm}^{-1}$ and $2850 \mathrm{~cm}^{-1}$ originate from the $\mathrm{C}-\mathrm{H}$ and $\mathrm{O}-\mathrm{H}$ stretch frequencies. The band at $1690 \mathrm{~cm}^{-1}$ represents the $\mathrm{C}=\mathrm{O}$ stretch frequency of lauric acid. The asymmetric $\mathrm{C}=\mathrm{O}\left(\mathrm{v}_{\mathrm{a}}\right)$ and the symmetric $\mathrm{C}=\mathrm{O}\left(\mathrm{v}_{\mathrm{s}}\right)$ stretch frequencies of cadmium laureate are located at $1540 \mathrm{~cm}^{-1}$ and $1420 \mathrm{~cm}^{-1}$, respectively. The weak band at $1690 \mathrm{~cm}^{-1}$ in the as-prepared cadmium laureate results from excess lauric acid. Compared to sodium laureate $\left(v_{a}=1563 \mathrm{~cm}^{-1}, v_{s}=1427 \mathrm{~cm}^{-1}\right)$ both, the asymmetric and the symmetric $\mathrm{C}=\mathrm{O}$ stretch frequencies of cadmium laureate, are shifted to lower frequencies. Thus, a monodentate coordination where the respective bands should shift into opposite directions, can be excluded [1]. From molar mass calculations ruling out a bridging bidentate coordination as well as from the frequency difference between the asymmetric and the symmetric $\mathrm{C}=0$ stretch mode, here $\Delta=120 \mathrm{~cm}^{-1}$ which is intermediate between monodentate and symmetric chelating bidentate, it can be concluded that the coordination mode of carboxylate with the cadmium ion is unsymmetrical chelating bidentate [1].

[1] Mesubi, M. A. An infrared study of zinc, cadmium, and lead salts of some fatty acids. Journal of Molecular Structure 1982, 81, 61-71. 


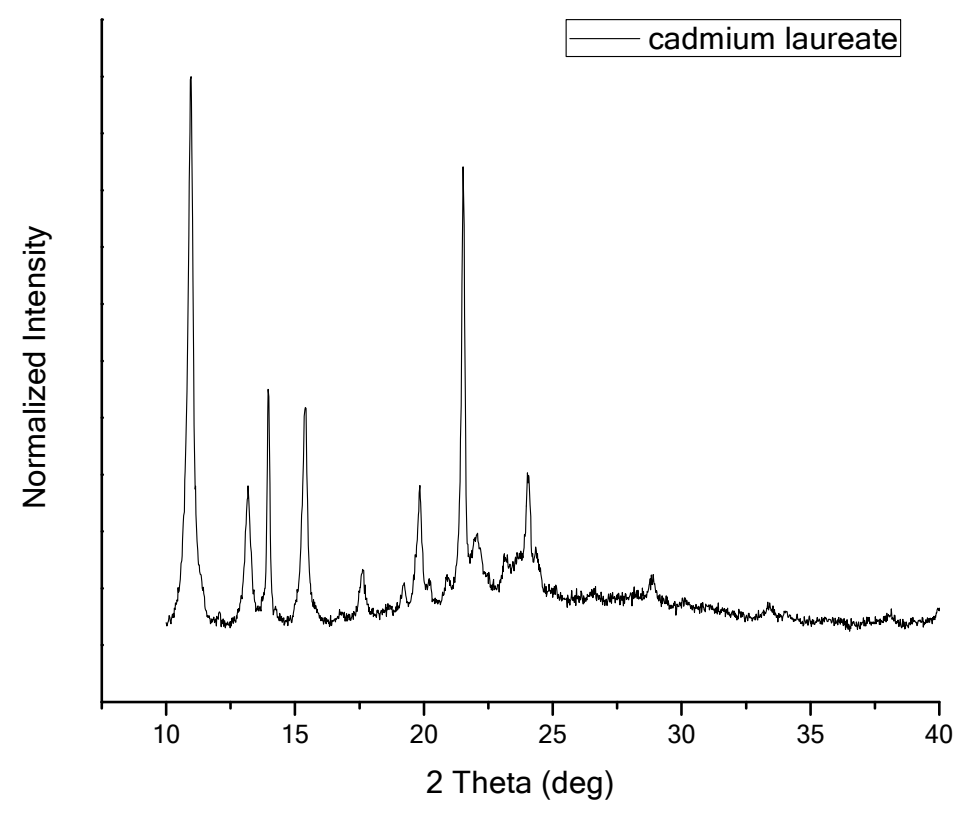

Figure S9. Powder XRD of the as-prepared cadmium laureate precursor. The sharp peaks indicate the crystalline structure. Reflexes at lower Bragg angles $\left(<30^{\circ}\right)$ are typical for organic and metal-organic compounds such as fatty acids and metal soaps.

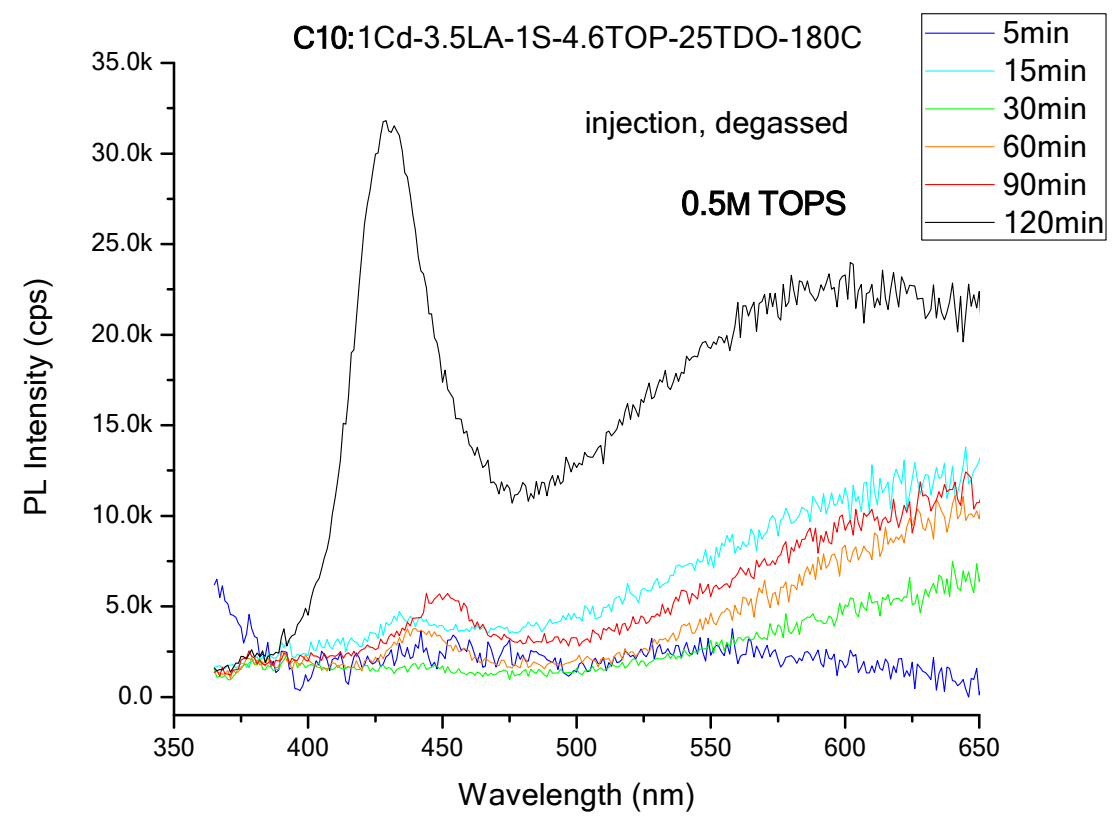

Figure S10. Temporal evolution of the PL of CdS QDs synthesized with $0.5 \mathrm{M}$ TOPS corresponding to $4.6 \mathrm{mmol}$ TOP. The Cd-to-S molar ratio is 1 . The PL intensity is extremely low and dominated by defect emission. 


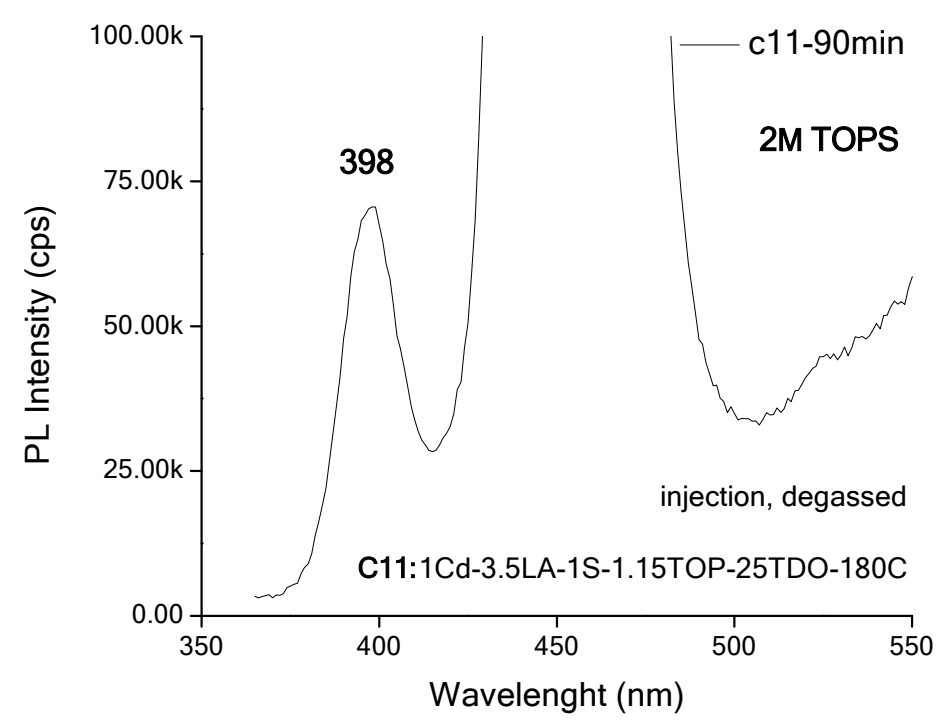

Figure S11. PL spectrum (zoom in) of a 90min CdS QDs sample synthesized with $2 \mathrm{M}$ TOPS corresponding to $1.15 \mathrm{mmol}$ TOP. The Cd-to-S molar ratio is 1 . The small signal located at $398 \mathrm{~nm}$ can be attributed to a second nucleation event.

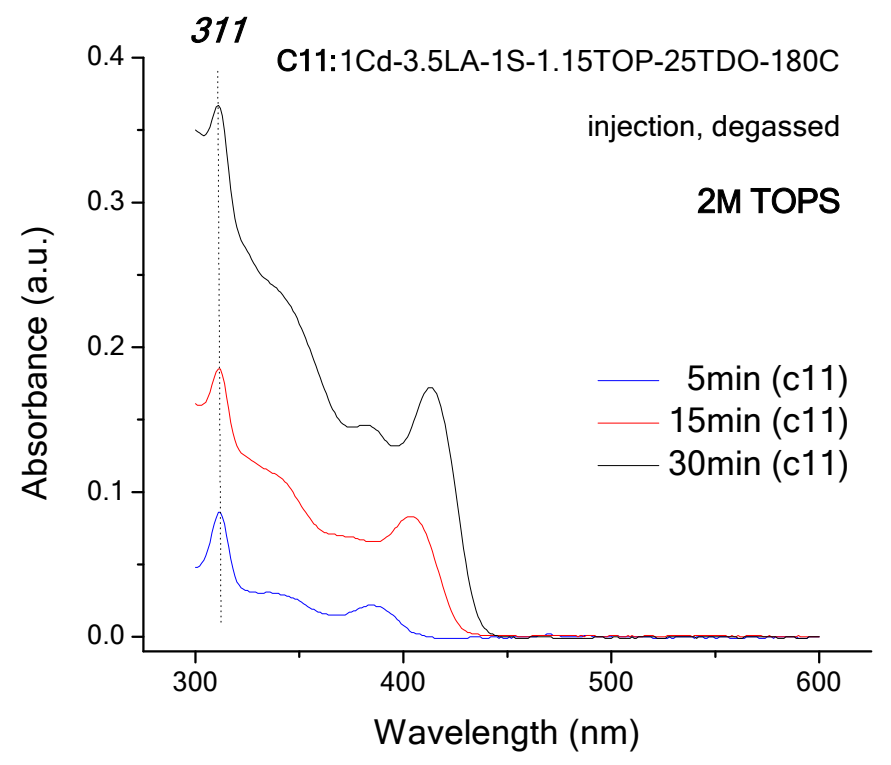

Figure S12. Absorption spectra of different CdS QD samples synthesized with 2M TOPS corresponding to $1.15 \mathrm{mmol}$ TOP. The Cd-to-S molar ratio is 1 . The reaction time is $5 \mathrm{~min}$ (blue line), $15 \mathrm{~min}$ (red line), and 30min (black line), respectively. The sharp and steady peak located at $311 \mathrm{~nm}$ can be attributed to CdS MSCs, in contrast to the continuously red-shifting broader peak which symbolizes the growth of CdS QDs. 

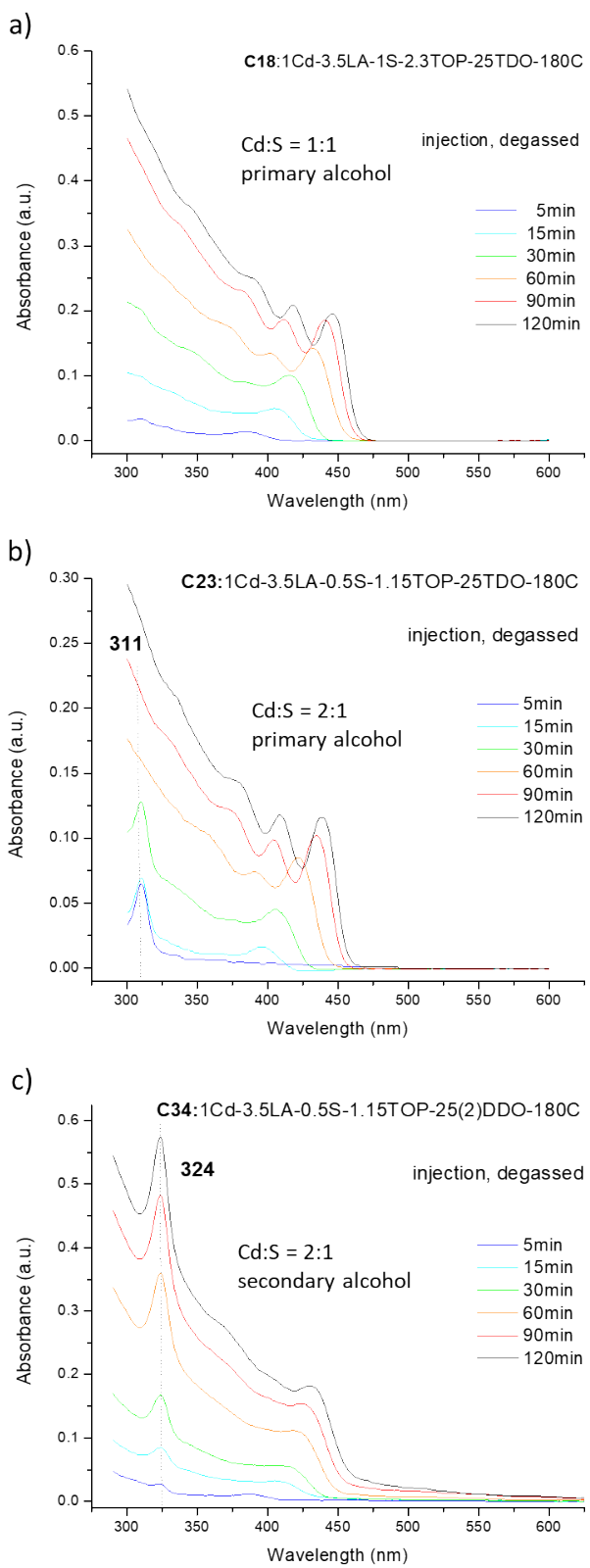

Figure S13. Temporal evolution of the absorption spectra of different CdS reactions in alcohol: a) primary alcohol (TDO) with a Cd-to-S molar ratio of 1 , b) primary alcohol (TDO) with excess $\mathrm{Cd}$, and c) secondary alcohol (2-dodecanol) with excess $\mathrm{Cd}$. The first reaction (a) shows the regular growth of CdS QDs which can be concluded from the continuous red-shift of the absorption signals. MCSs of CdS appeared in the beginning of the reaction (b), if an excess of $\mathrm{Cd}$ was used. This can be concluded from the sharp and steady peak at $311 \mathrm{~nm}$. In contrast, CdS MCSs with absorption peaking at $324 \mathrm{~nm}$ were observed throughout the entire reaction (c), if excess $\mathrm{Cd}$ in combination with 2dodecanol, a secondary alcohol, was used. 


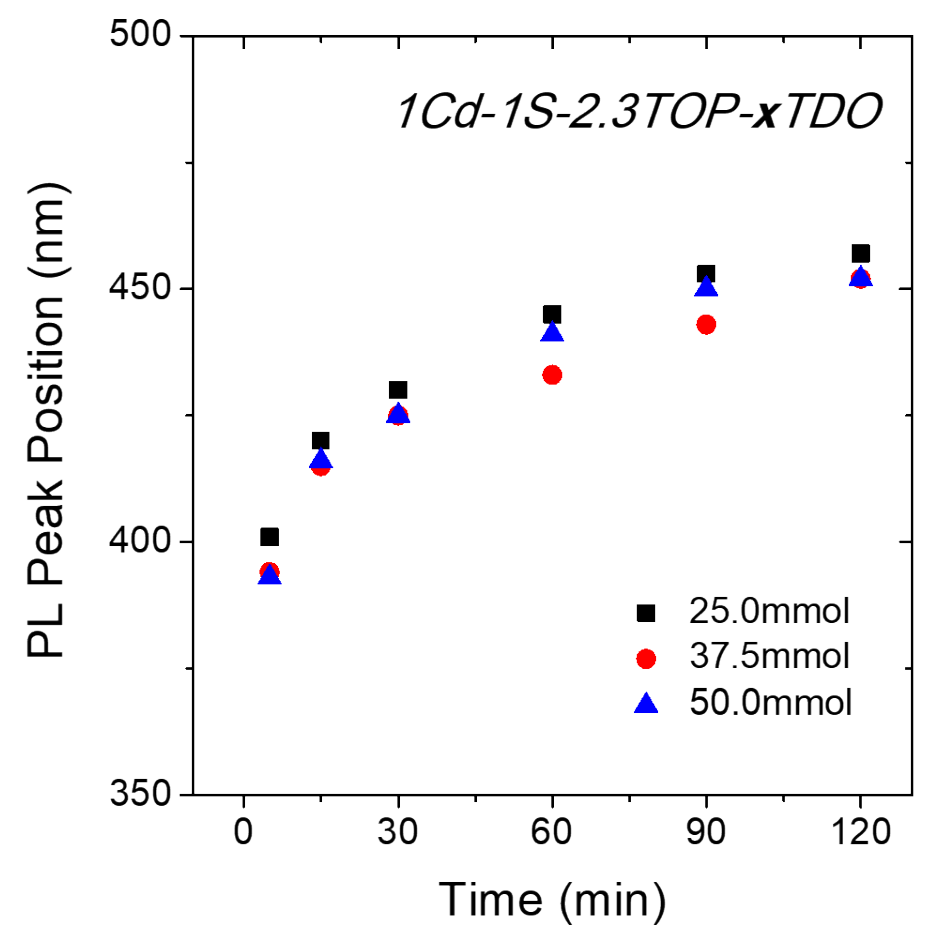

Figure S14. Temporal evolution of the PL peak position (growth curves) of CdS QDs synthesized from $\mathrm{Cd}(\mathrm{LA})_{2}$ and $1 \mathrm{M}$ TOPS in TDO at $180{ }^{\circ} \mathrm{C}$. Three reactions with different amounts of TDO or different precursor concentrations are compared. The feed molar ratio of each reaction is 1Cd-3.5LA-1S-2.3TOP-xTDO, with $x=25 \mathrm{mmol}$ (black square), $37.5 \mathrm{mmol}$ (red sphere), and $50 \mathrm{mmol}$ (blue triangle), respectively. 
a)
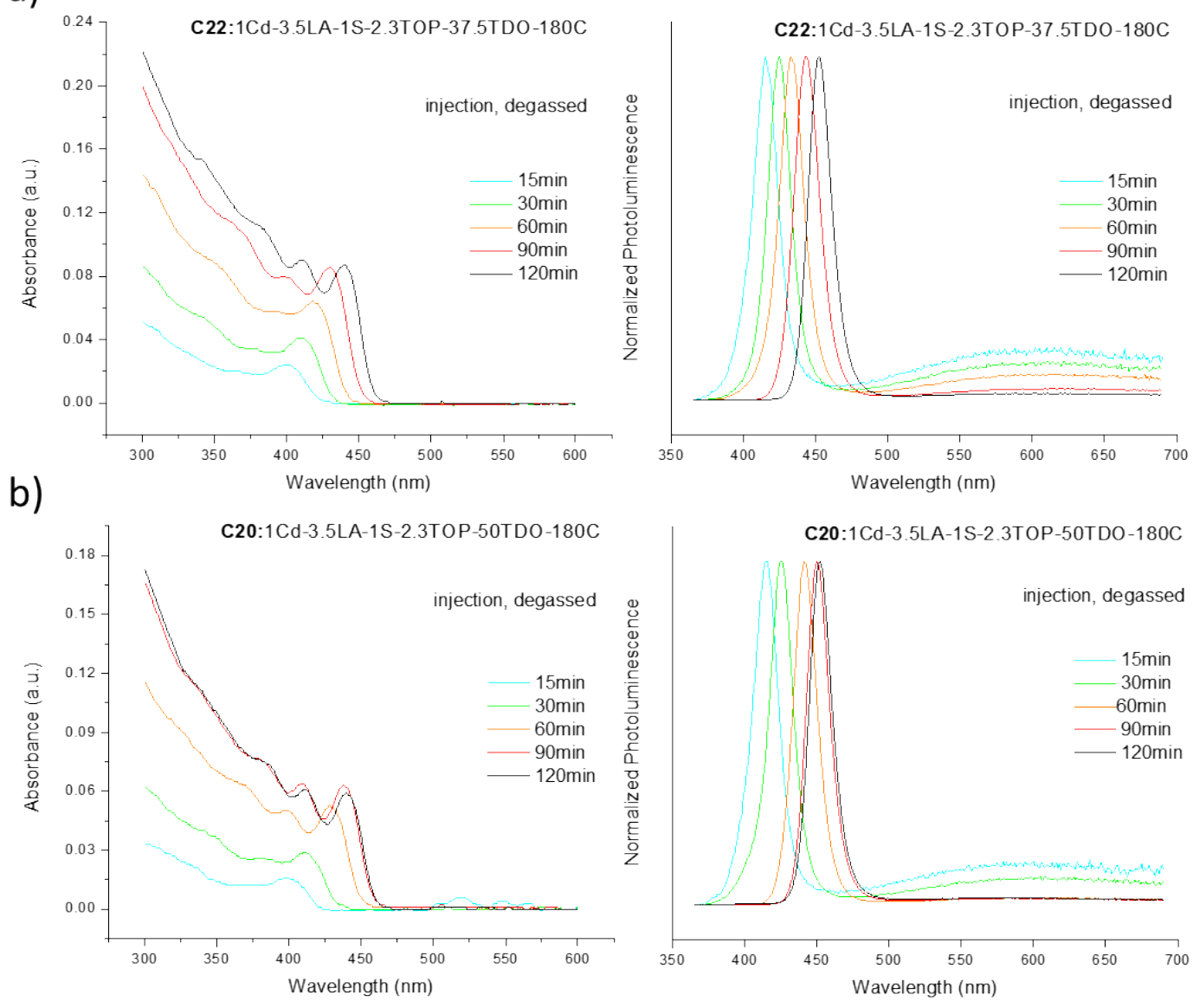

Figure S15. Temporal evolution of absorption (left) and PL (right) spectra of CdS QDs synthesized at different precursor concentrations: a) $37.5 \mathrm{mmol}$, and b) $50 \mathrm{mmol}$ of alcohol (TDO) were used. The initial concentration of $\mathrm{Cd}$ and $\mathrm{S}$ was $1 \mathrm{mmol}$, respectively. The corresponding spectra of the $25 \mathrm{mmol}$ TDO reaction are shown in Figure S7a (PL) and S13a (absorption). 


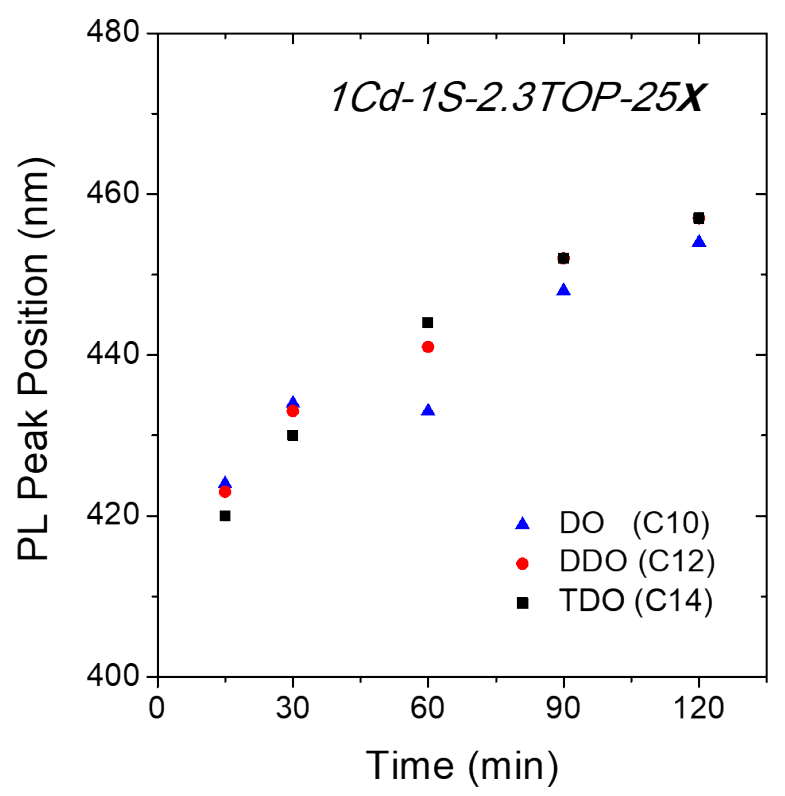

Figure S16. Temporal evolution of the PL peak position (growth curves) of CdS QDs synthesized from Cd(LA)2 and $1 \mathrm{M}$ TOPS in different fatty alcohols at $180{ }^{\circ} \mathrm{C}$. The feed molar ratio of each reaction is 1Cd-3.5LA-1S-2.3TOP-25X, with $\mathrm{X}$ (alcohol) $=$ TDO (black square), DDO (red sphere), and DO (blue triangle), containing 14, 12, and 10 carbons, respectively. 
a)
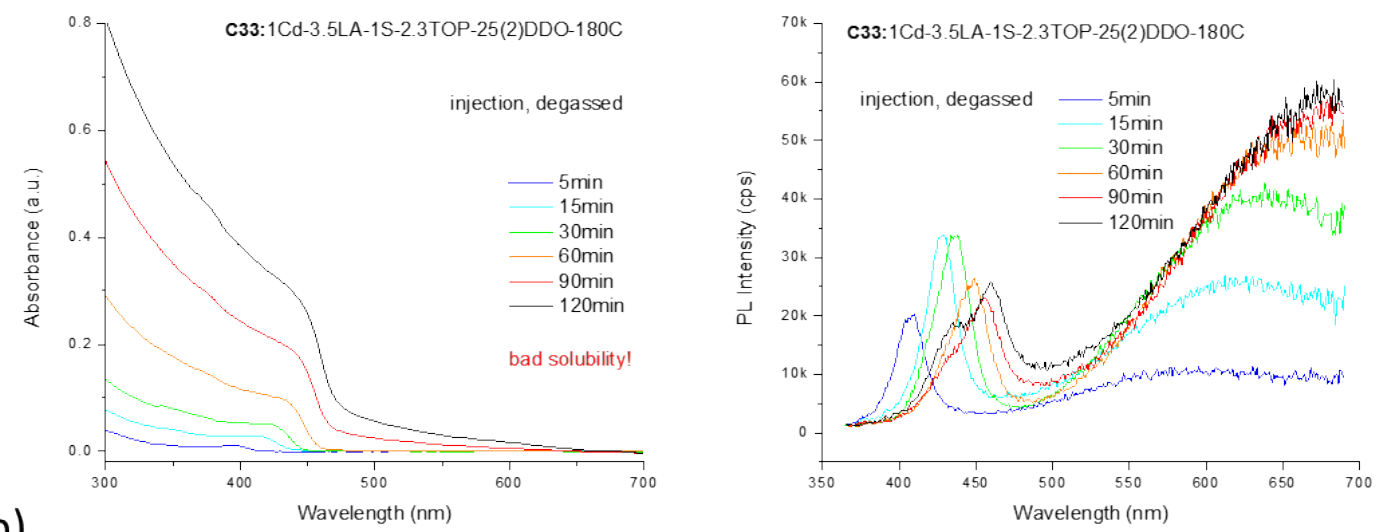

b)
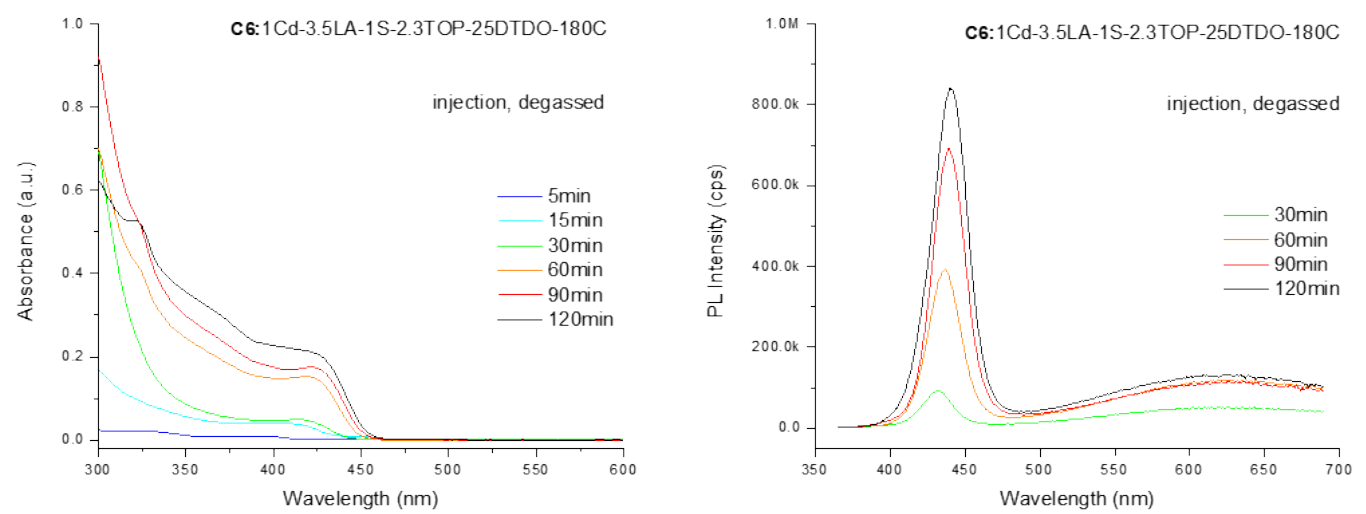

Figure S17. Temporal evolution of the absorption (left) and PL (right) spectra of CdS QDs synthesized in a) 2-dodecanol (secondary alcohol), and b) 2-decyl-1-tetradecanol (branched alcohol). In contrast to linear primary alcohols, here the PL is weak and dominated by defect emission. The corresponding samples exhibit a broad particle size dispersion (broad and flat absorption profile) and a bad solubility in $\mathrm{CHCl}_{3}$. The secondary linear alcohol has a stronger effect on the optical properties of CdS QDs than the primary branched one. 
a)

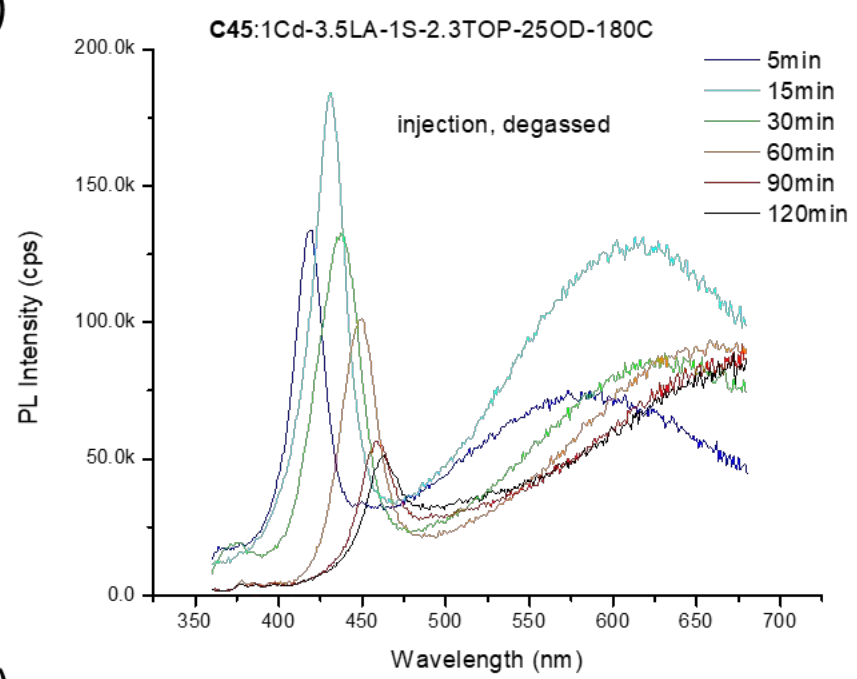

b)

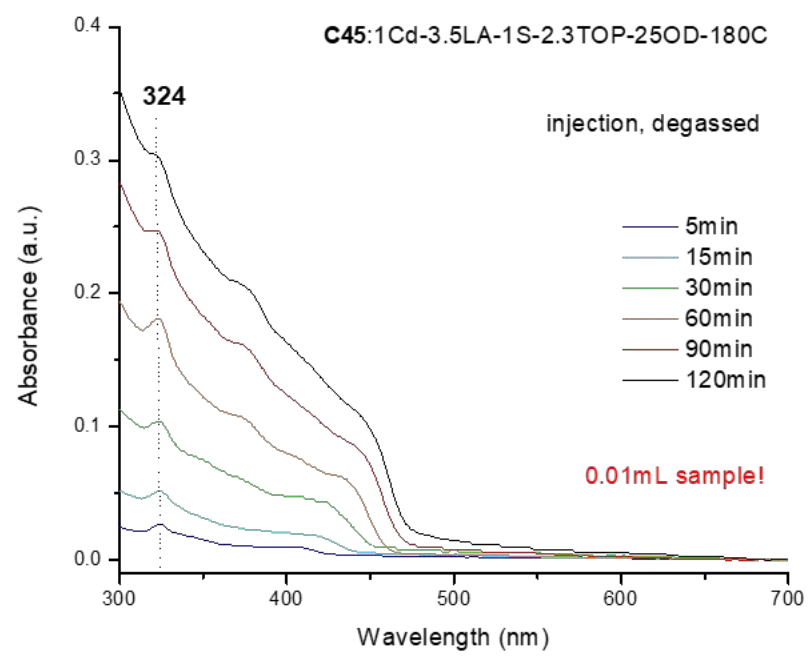

c)

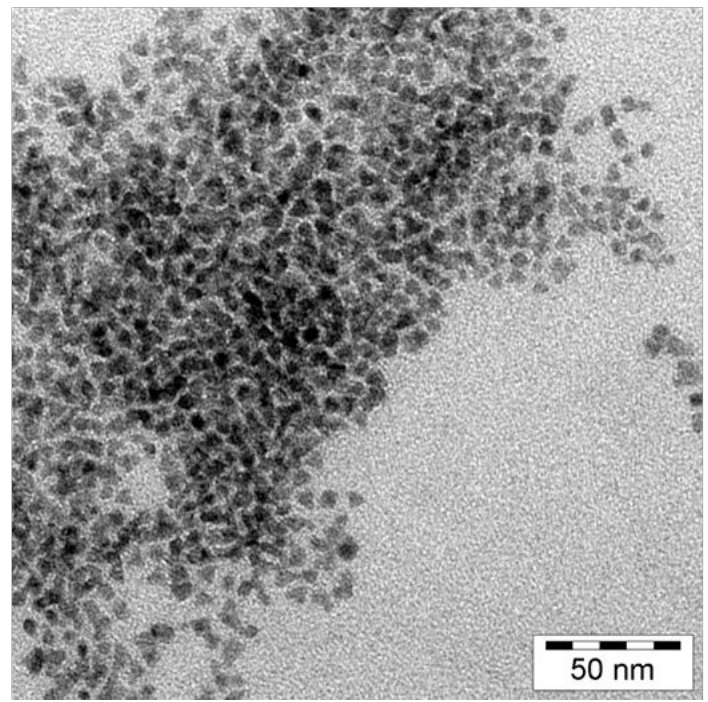

Figure S18. a) Absorption and b) PL evolution, and c) TEM micrograph (90min sample) of CdS QDs synthesized in non-coordinating octadecane (control experiment). The PL 
is dominated by defect emission. The broad and flat absorption profile indicates a broad particle size distribution which is confirmed by TEM showing an inhomogeneous sample with large and dense particle aggregates. Also, the existence of CdS 324-MSCs is observable throughout the entire reaction.

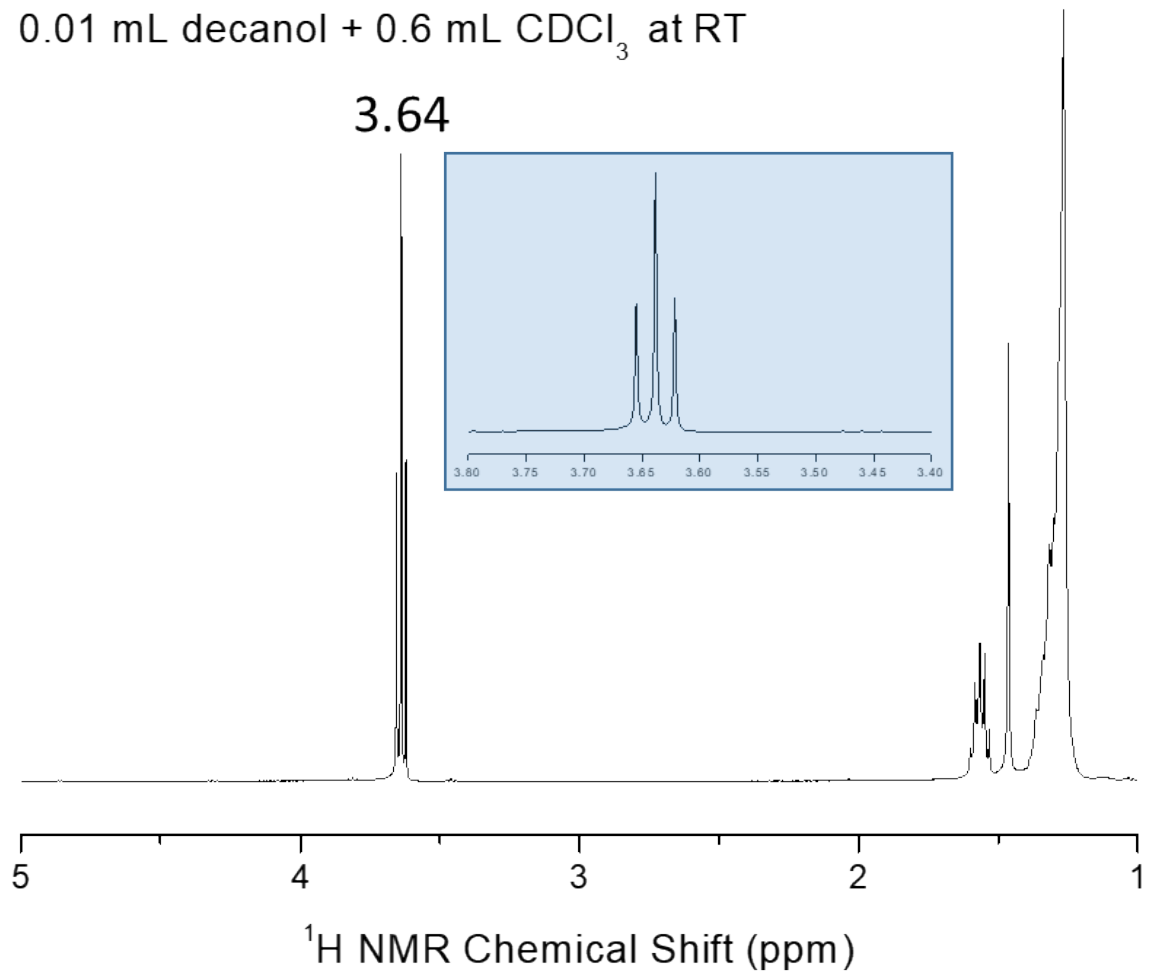

Figure S19. ${ }^{1} \mathrm{H}$ NMR spectrum of 1-decanol in $\mathrm{CDCl}_{3}$ at $\mathrm{RT}$ (reference). The blue inset shows the alcohol signal (triplet centered at $3.64 \mathrm{ppm}$ ) in enlargement. 


\section{APPENDIX}

The calculation of the reaction yield is based on the calculated amount of $\mathrm{Cd}$ found in a defined volume of a spherical particle considering the corresponding unit cell. The particle diameter is estimated from optical measurements and the particle concentration is determined by using the Lambert Beer formula. By comparing the known initial amount of $\mathrm{Cd}$ and the amount of $\mathrm{Cd}$ used for the formation of CdS QDs of a certain size and concentration the reaction yield can then be calculated as follows.

Note: The reaction yield obtained from this method is not very accurate and thus only suitable for qualitative comparison.

The concentration of the CdS QDs in chloroform was calculated using Lambert-Beer's law, $\mathrm{c}=\mathrm{A} / \varepsilon_{\lambda} \mathrm{d}$. $\mathrm{A}$ is the extinction or absorbance at the peak position $\lambda$ of the first excitonic transition of a given sample, $\varepsilon$ in $\mathrm{mol} / \mathrm{cm}$ is the molar extinction coefficient corresponding to the wavelength $\lambda, \mathrm{d}$ is the path length in $\mathrm{cm}$ of the radiation beam defined by the thickness of the cuvette, here $1 \mathrm{~cm}$, and $\mathrm{c}$ is the molar concentration in $\mathrm{mol} / \mathrm{L}$ of the CdS NCs. The size-dependent extinction coefficient in $\mathrm{M}^{-1} \mathrm{~cm}^{-1}$ was determined using the empirical fitting functions according to Yu et al. (Chem. Mater. 2003, 15, 2854-2860): $\varepsilon=5500 \Delta \mathrm{E}(\mathrm{D})^{2.5}$ with $\Delta \mathrm{E}$ the energy of the first excitonic transition in $\mathrm{eV}$ and $\mathrm{D}$ the QD diameter in $\mathrm{nm}$. The diameter $\mathrm{D}$ in $\mathrm{nm}$ can be calculated from the peak position $\lambda$ of the first excitonic transition in $\mathrm{nm}$ according to the following formula (Yu et al., Chem. Mater. 2003, 15, 2854-2860): $D=\left(-6.6521 * 10^{-8}\right) \lambda^{3}$ $+\left(1.9557^{*} 10^{-4}\right) \lambda^{2}-\left(9.2352 * 10^{-2}\right) \lambda+13.29$. 


\section{Reaction Yield of CdS QDs synthesized from CdLA and 1M TOPS in TDO with a feed molar ratio of $1 \mathrm{Cd}-3.5 \mathrm{LA}-1 \mathrm{~S}-2.3 \mathrm{TOP}-25 \mathrm{TDO}$ at $180^{\circ} \mathrm{C}(15 \mathrm{~min})$ :}

a)

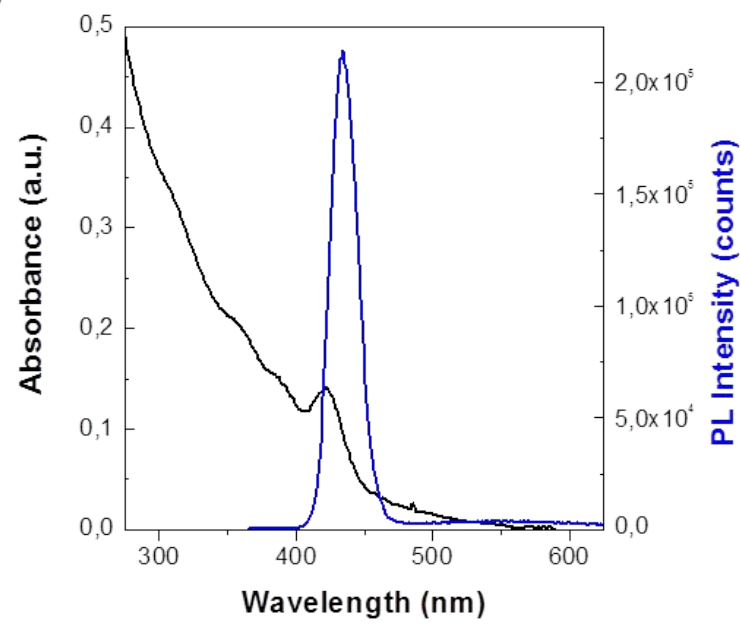

b)

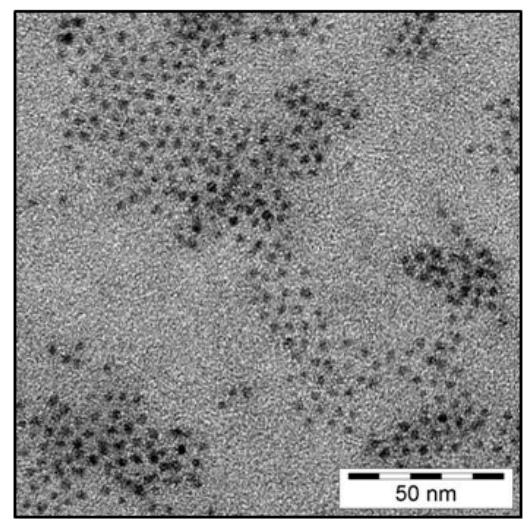

Total weight of reaction product: $7033 \mathrm{mg}$

Volume of dissolved reaction product: $\mathrm{V}=0.001 \mathrm{~L}$

Concentration of reaction product: $9.4 \mathrm{mg} / \mathrm{ml}$

Factor 749 for total weight

Concentration (according to Yu et al., Chem. Mater. 2003, 15, 2854-2860):

First excitonic peak: $422 \mathrm{~nm}$

Optical absorbance: 0.14

Diameter estimated from 1.excitonic peak: $4.15 \mathrm{~nm}$

Extinction coefficient at 1.excitonic peak: $\quad \varepsilon^{422}=5.67 * 10^{5} \mathrm{M}^{-1} \mathrm{~cm}^{-1}$

Molar Concentration: $\mathrm{c}=2.18^{*} 10^{-7} \mathrm{M}$

Amount of QDs: $\mathrm{n}^{\mathrm{QD}}=\mathrm{c} * \mathrm{~V}=2.18^{* 10^{-7}}(\mathrm{~mol} / \mathrm{L}) * 0.001 \mathrm{~L}=2.18^{*} 10^{-10} \mathrm{~mol}$

$$
\mathrm{N}^{\mathrm{QD}}=2.18 * 10^{-10} \mathrm{~mol} * 6.023 * 10^{23} \mathrm{QDs} / \mathrm{mol}=1.31 * 10^{14}
$$

Volume of $Q D: V Q D=(4 / 3) \pi r^{3}=1.33 * 3.14 *(2.08 * n m)^{3}=3.76 * 10^{-26} \mathrm{~m}^{3}$

Total Volume: $V^{\text {total }}=N^{Q D} * V^{Q D}=1.31 * 10^{14} Q D s * 3.76 * 10^{-26} \mathrm{~m}^{3} / \mathrm{QD}=4.93 * 10^{-12} \mathrm{~m}^{3}$

Volume of unit cell: $\mathrm{Vuc}=1.9693 * 10^{-28} \mathrm{~m}^{3} / \mathrm{uc}$

$\mathrm{a}^{\mathrm{Cds}}=0.5818 \mathrm{~nm}$ (Semiconductor Nanomaterials, Volume 6, pp 340, By Challa \& Kumar) Amount of unit cells: $\mathrm{N}^{\mathrm{uc}}=\left(\mathrm{V}^{\text {total }}\right) / \mathrm{V}^{\mathrm{uc}}=4.93^{*} 10^{-12} \mathrm{~m}^{3} / 1.9693 * 10^{-28} \mathrm{~m}^{3} \mathrm{uc}^{-1}=2.50^{*} 10^{16} \mathrm{uc}$ Total amount of $\mathrm{Cd}$ atoms: $\mathrm{N}^{\mathrm{Cd}}=(4 \text { atoms } / \mathrm{uc})^{*} \mathrm{~N}^{\mathrm{uc}}=4$ atoms uc ${ }^{-1} * 2.5^{*} 10^{16} \mathrm{uc}=1.00^{*} 10^{17}$ atoms Amount of $\mathrm{Cd}$ in mol: $\mathrm{n}^{\mathrm{Cd}}=\mathrm{N}^{\mathrm{Cd}} / \mathrm{A}=1.0^{*} 10^{17}$ atoms $/ 6.023 * 10^{23}$ atoms mol ${ }^{-1}=1.66 * 10^{-7} \mathrm{~mol}$ Amount of $\mathrm{Cd}$ in the whole batch: $1.66 * 10^{-7} \mathrm{~mol}^{*} 749=124 * 10^{-6} \mathrm{~mol}=0.124 \mathrm{mmol}$

Reaction yield $(\mathrm{TDO})=0.124 \mathrm{mmol} \mathrm{Cd}^{\mathrm{QD}} / 1 \mathrm{mmol} \mathrm{Cd}^{\mathrm{CdLa} *} 100 \%=12.4 \%$ 


\section{Reaction Yield of CdS QDs synthesized from CdLA and 1M TOPS in OD with a feed molar ratio of $1 \mathrm{Cd}-3.5 \mathrm{LA}-1 \mathrm{~S}-2.3 \mathrm{TOP}-250 \mathrm{D}$ at $180^{\circ} \mathrm{C}$ (15 $\left.\mathrm{min}\right)$ :}

a)

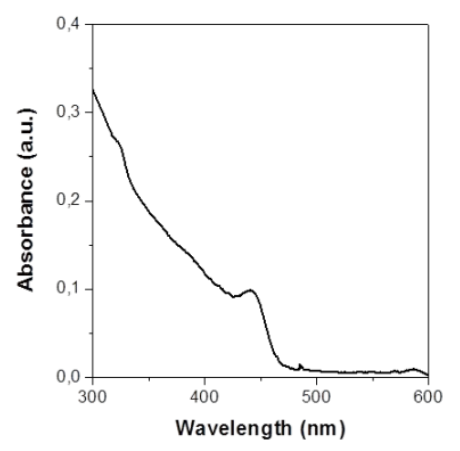

b)

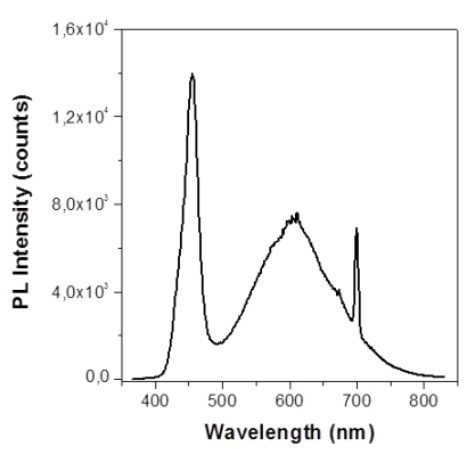

c)

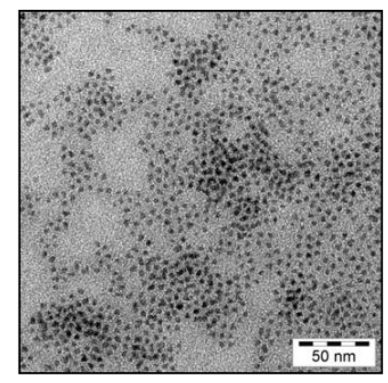

Total weight of reaction product: $8036 \mathrm{mg}$

Volume of dissolved reaction product: $\mathrm{V}=0.001 \mathrm{~L}$

Concentration of reaction product: $11.5 \mathrm{mg} / \mathrm{ml} \mathrm{CHCl} 3$

Factor 699 for total amount of cadmium

Concentration (according to Yu et al., Chem. Mater. 2003, 15, 2854-2860):

First excitonic peak: $442 \mathrm{~nm}$

Optical absorbance: 0.09

Diameter estimated from 1. excitonic peak: $4.93 \mathrm{~nm}$

Extinction coefficient at 1. excitonic peak: $\varepsilon^{442}=8.46 * 10^{5} \mathrm{M}^{-1} \mathrm{~cm}^{-1}$

Molar Concentration: $\mathrm{c}=1.06 * 10^{-7} \mathrm{M}$

Amount of QDs: $\mathrm{n}^{\mathrm{QD}}=\mathrm{c} * \mathrm{~V}=1.06 * 10^{-7} \mathrm{~mol} / \mathrm{L} * 0.001 \mathrm{~L}=1.06 * 10^{-10} \mathrm{~mol}$

$$
\mathrm{N}^{\mathrm{QD}}=1.06 * 10^{-10} \mathrm{~mol} * 6.023 * 10^{23} \mathrm{QDs} / \mathrm{mol}=6.38 * 10^{13}
$$

Volume of QD: $V^{Q D}=(4 / 3) \pi r^{3}=1.33 * 3.14 *(2.46 * n m)^{3}=6.22 * 10^{-26} \mathrm{~m}^{3}$

Total Volume: $V^{\text {total }}=\mathrm{N}^{\mathrm{QDs}} * \mathrm{~V} \mathrm{QD}=6.38 * 10^{13} \mathrm{QDs} * 6.22 * 10^{-26} \mathrm{~m}^{3} / \mathrm{QD}=3.97 * 10^{-12} \mathrm{~m}^{3}$

Volume of unit cell: Vuc $=1.9693 * 10^{-28} \mathrm{~m}^{3} / \mathrm{uc}$

$\mathrm{a}^{\mathrm{CdS}}=0.5818 \mathrm{~nm}$ (Semiconductor Nanomaterials, Volume 6, pp 340, by Challa \& Kumar)

Amount of unit cells: $\mathrm{N}^{\mathrm{uc}}=\mathrm{V}^{\text {total }} / \mathrm{V}^{\mathrm{uc}}=3,97 * 10^{-12} \mathrm{~m}^{3} / 1.9693 * 10^{-28} \mathrm{~m}^{3} \mathrm{uc}^{-1}=2.02 * 10^{16} \mathrm{uc}$

Amount of Cd atoms: $\mathrm{N}^{\mathrm{Cd}}=(4 \text { atoms } / \mathrm{uc})^{*} \mathrm{~N}^{\mathrm{uc}}=4 \mathrm{uc}^{-1} * 2.02 * 10^{16} \mathrm{uc}=8,08 * 10^{16}$

Amount of $\mathrm{Cd}$ in mol: $\mathrm{n}^{\mathrm{Cd}}=\mathrm{N}^{\mathrm{Cd}} / \mathrm{A}=8,08 * 10^{16}$ atoms $/ 6.023 * 10^{23}$ atoms mol-1 $=1.34 * 10^{-7} \mathrm{~mol}$

Amount of $\mathrm{Cd}$ in the whole batch: $1.34 * 10^{-7} \mathrm{~mol} * 699=93.6^{*} 10^{-6} \mathrm{~mol}=0.0936^{*} 10^{-3}=0.0936 \mathrm{mmol}$

Reaction yield $(O D)=0.0936 \mathrm{mmol} C d^{Q D} / 1 \mathrm{mmol} \mathrm{Cd}^{\mathrm{CdLa}} * 100 \%=9.36 \%$ 